\title{
Better candy for the false lumen
}

\author{
Bradley G. Leshnower, MD
}

\author{
From the Division of Cardiothoracic Surgery, Joseph B. Whitehead Department of Surgery, Emory School of \\ Medicine, Atlanta, Ga. \\ Disclosures: Author has nothing to disclose with regard to commercial support. \\ Received for publication Jan 7, 2018; accepted for publication Jan 12, 2018; available ahead of print Feb 10, 2018 \\ Address for reprints: Bradley G. Leshnower, MD, Division of Cardiothoracic Surgery, Emory University School \\ of Medicine, 1365 Clifton Rd NE, Suite A2257, Atlanta, GA 30322 (E-mail: bleshno@emory.edu). \\ J Thorac Cardiovasc Surg 2018;155:1973 \\ $0022-5223 / \$ 36.00$ \\ Copyright (C) 2018 by The American Association for Thoracic Surgery \\ https://doi.org/10.1016/j.jtcvs.2018.01.020
}

Retrograde false lumen (FL) perfusion is the Achilles heel of thoracic endovascular aortic repair (TEVAR) in patients with chronic type B aortic dissection (CTBAD). Although TEVAR eliminates antegrade FL perfusion, retrograde FL perfusion via distal aortic fenestrations can prevent complete FL thrombosis, thus maintaining FL patency. Another impediment to the success of TEVAR in CTBAD is the rigidity of the dissection flap. The fibrotic, immobile flap prevents expansion of the stented true lumen and acts as a scaffold that maintains FL geometry, thus preventing a reduction in size of the FL. All of these factors may contribute to persistent perfusion and pressurization of the FL, which can result in aneurysmal expansion and failure of endovascular therapy.

Innovative endovascular techniques have been developed to arrest retrograde perfusion of the thoracic FL. The "knickerbocker" technique involves balloon rupture of the dissection flap to oppose it to the aortic wall. This results in obliteration of a segment of the FL that prevents retrograde perfusion proximal to this segment. ${ }^{1}$ The other main technique involves FL embolization using a variety of devices, including vascular plugs to induce FL thrombosis. However, this technique is unsuccessful if the FL is significantly aneurysmal, because the currently available vascular plugs are too small too occlude the lumen. The original "candy-plug" technique was developed to address this problem. A thoracic aortic stent graft is partially deployed on the back table, narrowed down in the midpoint of the graft with an external circumferential suture, repackaged, and deployed in the FL. The narrowed segment is subsequently occluded with a vascular plug, thus creating a "blind pouch" preventing retrograde FL perfusion proximal to the plug. ${ }^{2}$ The current article ${ }^{3}$ in the Journal reports a modification of the candy-plug technique by replacing the narrowing suture with a short segment of an iliac stent graft limb telescoped over the larger stent graft to create a waist for vascular plug placement. Wu and colleagues ${ }^{3}$ present this as a more durable, precise technique because the narrowed segment is externally constrained by $20 \mathrm{~mm}$ of stent

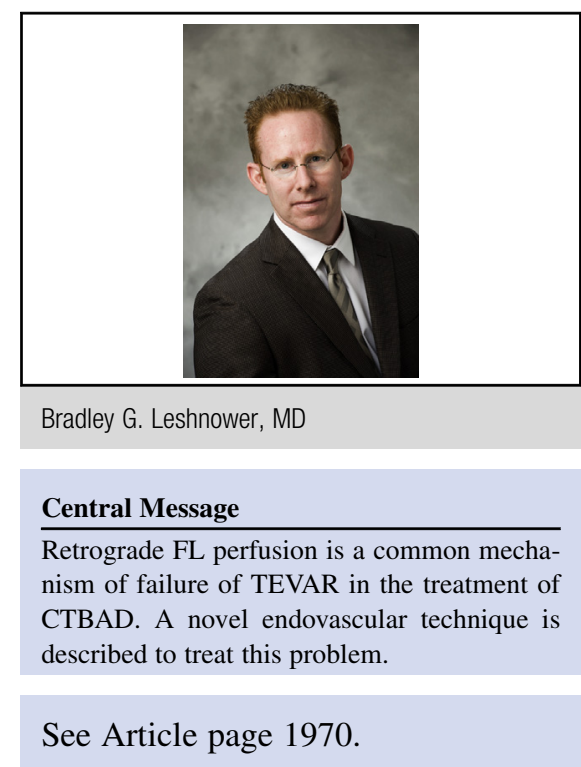

graft rather than a single suture, and the diameter is defined by the diameter of the iliac limb graft. This will also eliminate the chance that the nosecone will get caught in the "waist" and that a properly sized vascular plug can be selected.

This modification represents an improvement on the original "candy plug" technique. However, if endovascular therapy is to continue to evolve and improve for CTBAD, a disease-specific device needs to be developed for the FL that is short $(<100 \mathrm{~mm})$, has a large $(20-40 \mathrm{~mm})$ open distal end, and has a smaller (16-22 mm) occluded proximal end that is compliant so that it can conform to all of the various crescentic shapes of the FL. This type of device would be deployed in the FL after true lumen endograft coverage is extended to the celiac artery to cover all thoracic intimal tears. This strategy optimizes the environment for complete thoracic FL thrombosis and aneurysm sac stabilization or reduction. This would be truly better candy for the FL.

\section{References}

1. Kolbel T, Carpenter SW, Lohrenz C, Tsilimparis N, Larena-Avellaneda A Debus ES. Addressing persistent false lumen flow in chronic aortic dissection: the knickerbocker technique. J Endovasc Ther. 2014;21:117-22.

2. Kolbel T, Lohrenz C, Kieback A, Diener H, Debus ES, Larena-Avellaneda A Distal false lumen occlusion in aortic dissection with a homemade extra-large vascular plug: the candy-plug technique. J Endovasc Ther. 2013;20:484-9.

3. Wu IH, Chan CY, Luo CM, Wang SS. Modified candy-plug device for aneurysmal false lumen occlusion in chronic type B aortic dissection. J Thorac Cardiovasc Surg. 2018;155:1970-2. 